\title{
In vitro antiviral activity of Griffithsin against porcine epidemic diarrhea virus
}

\author{
Lan $\mathrm{Li}^{1} \cdot$ Xiaoming $\mathrm{Yu}^{1} \cdot$ Haoming Zhang ${ }^{1} \cdot$ Haiwei Cheng ${ }^{1} \cdot$ Liting Hou $^{1} \cdot$ Qisheng Zheng ${ }^{1} \cdot$ Jibo Hou ${ }^{1,2}$
}

Received: 29 September 2018 / Accepted: 2 January 2019 / Published online: 14 January 2019

(c) Springer Science+Business Media, LLC, part of Springer Nature 2019

\begin{abstract}
Griffithsin is a lectin with potent antiviral activity against enveloped viruses. The objective of this study was to assess Griffithsin's inhibitory effect on porcine epidemic diarrhea virus (PEDV). The results showed that Griffithsin reduced PEDV infection of Vero cells by approximately $82.8 \%$. Moreover, using time-of-addition assays and RT-qPCR, we found that delayed addition of Griffithsin had a weaker inhibitory effect on PEDV than earlier treatment. The mechanism of Griffithsin's action against PEDV involved both preventing viral attachment to host cells and disrupting cell-to-cell transmission; its dual mode of action distinguished Griffithsin from most other antiviral drugs. In conclusion, Griffithsin was identified as a potent PEDV inhibitor and may represent a candidate drug for preventing PEDV infection.
\end{abstract}

Keywords Griffithsin · Antiviral · Porcine epidemic diarrhea virus $\cdot$ Lectin

\section{Introduction}

Edited by Zhen F. Fu.

Lan Li and Xiaoming Yu have contributed equally as first authors.

Qisheng Zheng

immun_tech@163.com

$\triangle$ Jibo Hou

houjiboccvv@163.com

Lan Li

lanli99@foxmail.com

Xiaoming Yu

yxm123abc@126.com

Haoming Zhang

7231022@126.com

Haiwei Cheng

chw5673@126.com

Liting Hou

houxyzmn@163.com

1 National Research Center of Engineering and Technology for Veterinary Biologicals, Jiangsu Academy of Agricultural Sciences, Nanjing 210014, Jiangsu, China

2 Jiangsu Co-innovation Center for Prevention and Control of Important Animal Infectious Diseases and Zoonoses, Yangzhou 225009, Jiangsu, China
Griffithsin, a high-mannose-specific lectin from Griffithsia spp. marine red algae [1], has broad-spectrum antiviral activity [2]. Griffithsin is the most potent anti-human immunodeficiency virus (HIV) agent described to date, with a 50\% effective concentration $\left(\mathrm{EC}_{50}\right)$ in the low picomolar range [3]. Moreover, Griffithsin exerts antiviral activity against multiple enveloped viruses including severe acute respiratory syndrome corona virus (SARS-CoV) [4], Middle East respiratory syndrome coronavirus (MERS-CoV) [5], hepatitis $\mathrm{C}$ virus (HCV) [6], herpes simplex virus type 2 (HSV-2) [7] and Japanese encephalitis virus (JEV) [8, 9], and at least one non-enveloped virus (human papilloma virus) [10]. Griffithsin showed a favorable safety profile, with no T-cell activating activity and little impact on cytokine and chemokine release by immune cells [11], as well as an excellent stability over a broad range of $\mathrm{pHs}$, temperatures and protease exposures [12, 13]. All of these characteristics make Griffithsin an attractive candidate for development as an antiviral therapeutic, but its activity against porcine epidemic diarrhea virus (PEDV) remains unexplored.

PEDV infects pig populations in Asia, Europe and North America, causing huge economic losses [14]. PEDV is a highly contagious enteric infection characterized by acute watery diarrhea, vomiting and dehydration [15]. Pigs of all ages can be infected by PEDV, but the infection is especially 
serious in suckling piglets with morbidity and mortality often reaching $100 \%$.

As an enteropathogenic coronavirus, PEDV has a singlestranded, positive-sense RNA genome approximately $28 \mathrm{~kb}$ in size and encoding four structural proteins: the spike (S), envelope (E), membrane $(\mathrm{M})$ and nucleocapsid $(\mathrm{N})$ protein [16]. The PEDV S protein is a major type I glycoprotein located on the viral surface [17] containing 27-29 putative $\mathrm{N}$-glycosylation sites and plays an important role in viral entry, making it an attractive target for chemotherapeutic interventions.

In this study, we showed that Griffithsin inhibited PEDV infection of Vero cells. We also elucidated the detailed mechanism of Griffithsin's inhibitory action on PEDV infection.

\section{Materials and methods}

\section{Cells and viruses}

Vero cells (an African green monkey-derived kidney cell line) were maintained in Dulbecco's modified Eagle's medium (DMEM) (Gibco, USA) supplemented with $10 \%$ (v/v) fetal bovine serum at $37{ }^{\circ} \mathrm{C}$ under an atmosphere of $5 \% \mathrm{CO}_{2}$.

The Chinese PEDV isolate NJ-PEDV was isolated, identified and stored in our laboratory at the National Research Center of Engineering and Technology for Veterinary Biologicals, Jiangsu Academy of Agricultural Science. The NJPEDV strain was propagated in Vero cells, and viral stock was titered to determine its $\operatorname{TCID}_{50}$.

\section{Protein production}

Protein production was performed as described in the $\mathrm{pET}$ system manual (Novagen, USA) in E. coli BL21 (DE3) cells. The Griffithsin gene (GenBank: FJ594069) was codon-optimized for $E$. coli expression, synthesized and cloned into the pUC57 vector by GenScript (Nanjing, China). Then recombinant Griffithsin gene was introduced into pET32a vector to obtain the recombinant expression plasmid pET32aGriffithsin. Then the plasmid was transformed into competent $E$. coli BL21 (DE3) cells to obtain the recombinant $E$. coli BL21 pET32a-Griffithsin strain which was selected by ampicillin and chloramphenicol, meanwhile pET32a was as a negative control. The recombinant $E$. coli strains were grown overnight at $37{ }^{\circ} \mathrm{C}$ in LB broth. Then the overnight cultures were 100 -fold diluted in $400 \mathrm{~mL}$ of fresh LB broth at $37{ }^{\circ} \mathrm{C}$ and induced with $1 \mathrm{mM}$ isopropyl-beta-D-thiogalactopyranoside (IPTG). After further incubation for $24 \mathrm{~h}$ at $15{ }^{\circ} \mathrm{C}$, the protein Griffithsin was extracted and purified using a $5 \mathrm{~mL} \mathrm{Ni}^{2+}$-Sepharose HisTrap HPTM affinity column
(GE Healthcare, Sweden) elution with $300 \mathrm{mM}$ imidazole in PBS. The protein was dialyzed to remove imidazole, following by endotoxin removal using ToxinEraser ${ }^{\mathrm{TM}}$ Endotoxin Removal Kit (GenScript, China) and filter sterilization, then quantified using a BCA Protein Assay Reagent Kit (Pierce, USA). Finally, SDS-PAGE and western blotting were used to analyze protein production.

\section{Binding of Griffithsin to PEDV virions by enzyme-linked immunosorbent assay (ELISA)}

Flat-bottom 96-well microtiter plates (Nunc, Maxiscorp, MD, USA) were coated with either $100 \mu \mathrm{L}$ of PEDV ( $1 \mu \mathrm{g} /$ $\mathrm{mL}$; purified by ultracentrifugation) or $5 \%(\mathrm{w} / \mathrm{v})$ bovine serum albumin (BSA) in $50 \mathrm{mM}$ carbonate buffer, $\mathrm{pH} 9.6$. After overnight incubation at $4{ }^{\circ} \mathrm{C}$, the wells were blocked with phosphate-buffered saline (PBS) containing $0.05 \%(\mathrm{v} / \mathrm{v})$ Tween-20 (PBST) and 5\% BSA for $2 \mathrm{~h}$ at $37{ }^{\circ} \mathrm{C}$. Titrated concentrations of Griffithsin in a volume of $100 \mu \mathrm{L}$ were added to the wells. For competition ELISA, various dilutions of Griffithsin were pre-incubated with D- $(+)$-mannose or D-(+)-glucose. An anti-His tag antibody (Boster, Wuhan, China) and horseradish peroxidase-conjugated (HRP) secondary antibody (Boster, Wuhan, China) were used to detect Griffithsin binding. For HRP detection, 3,3',5,5'-tetramethylbenzidine (TMB) substrate was added and the reaction was stopped with $2 \mathrm{M} \mathrm{H}_{2} \mathrm{SO}_{4}$. The absorbance was measured using a microplate spectrophotometer (BioTec) at a wavelength of $450 \mathrm{~nm}$.

\section{Cytotoxicity assay}

Cytotoxicity was evaluated using a MTT assay. Vero cells were seeded in wells of a 96-well plate at a density of $2 \times 10^{4}$ cells per well. The next day, various concentrations of Griffithsin were added to cells. After incubating for $48 \mathrm{~h}$, MTT was added to each well and incubated for an additional $4 \mathrm{~h}$. The supernatant was removed, dimethyl sulfoxide was added to dissolve the colored formazan crystal and the absorbance was measured at a wavelength of $490 \mathrm{~nm}$.

\section{Antiviral activity of Griffithsin}

Vero cells were seeded in wells of 96-well plates and cultured overnight at $37{ }^{\circ} \mathrm{C}$ under an atmosphere of $5 \%$ $\mathrm{CO}_{2}$. Various concentrations of Griffithsin $(0-8 \mu \mathrm{g} / \mathrm{mL})$ were incubated with PEDV for $30 \mathrm{~min}$ at room temperature and subsequently used to infect cells at a multiplicity of infection (MOI) of 3 and 5 for $1 \mathrm{~h}$ at $37^{\circ} \mathrm{C}$. The cells were washed with PBS, and fresh medium containing $2 \%$ fetal bovine serum was added. In a control group, Griffithsin was pre-incubated with $100 \mathrm{mM} \mathrm{D}-(+)$-mannose before incubation with PEDV. After $24 \mathrm{~h}$, the cells were 
fixed with pre-cooled methanol for $10 \mathrm{~min}$, air-dried, and blocked with PBS containing 3\% BSA for $1 \mathrm{~h}$. Then, cells were then incubated with mouse anti-PEDV monoclonal antibody (diluted 1:200; a generous gift from Haoming Zhang) and FITC-conjugated goat anti-mouse IgG (diluted 1:50; Boster, Wuhan, China) for $1 \mathrm{~h}$ each at $37^{\circ} \mathrm{C}$. After washing, the cells were stained with DAPI for $10 \mathrm{~min}$ at room temperature, washed again and observed using a Cytation $^{\mathrm{TM}}$ five Cell Imaging Multi-Mode Reader (BioTek).

\section{Time-of-addition assay}

The time-of-addition assay for Griffithsin was conducted as previously described with some modifications [18]. Subconfluent Vero cell monolayers were infected with PEDV at a MOI of 3 for $1 \mathrm{~h}$ at $37{ }^{\circ} \mathrm{C}$. After washing with PBS, $8 \mu \mathrm{g} /$ $\mathrm{mL}$ Griffithsin was added to the cells either before $(-1 \mathrm{~h})$, during $(0 \mathrm{~h})$ or after $(1,2,4,6,8,12$, or $24 \mathrm{~h})$ PEDV infection. Infected cells not treated with Griffithsin were used as a control. After $24 \mathrm{~h}$, cells were collected and subjected to RT-qPCR.

Total RNA was extracted using a MiniBEST Universal RNA Extraction Kit (TaKaRa, Osaka, Japan). RNA was reverse transcribed into first-strand cDNA using PrimeScript ${ }^{\mathrm{TM}}$ Reverse Transcriptase (TaKaRa). RT-qPCR was performed with a LightCycler 480 II System (Roche, Basel, Switzerland) using the EvaGreen $2 \times$ qPCR MasterMixNo Dye kit (abm, Canada) according to the manufacturer's recommendations. The forward primer (FP) and reverse primer (RP) for the PEDV $\mathrm{M}$ gene and the GAPDH gene were as follows: PEDV-FP:5'-ACTCTGCGTTCTTGTATG -3', PEDV-RP:5'-CAACCGAATGCTATTGAC-3', GAPDHFP: 5'-CCTTCCGTGTCCCTACTGCCAAC-3', GAPDHRP: 5'-GACGCCTGCTTCACCACCTTCT-3'. Data were analyzed using the $2^{-\Delta \Delta \mathrm{Ct}}$ method. The mean RNA level of control cells not treated with Griffithsin was assigned a value of 1 . Each assay was performed in triplicate.

\section{Effect of Griffithsin on viral entry stages}

For the attachment assay, Vero cells in wells of 96-well plates were pre-cooled at $4{ }^{\circ} \mathrm{C}$ for $30 \mathrm{~min}$ and simultaneously infected with PEDV (MOI $=3$ ) and treated with Griffithsin for $1 \mathrm{~h}$ at $4{ }^{\circ} \mathrm{C}$. For the penetration assay, PEDV virions were allowed to attach to cells at $4{ }^{\circ} \mathrm{C}$ for $1 \mathrm{~h}$. After washing with PBS, the cells were simultaneously warmed to $37{ }^{\circ} \mathrm{C}$ and treated with Griffithsin for an additional $1 \mathrm{~h}$. Finally, the cells were washed with PBS and collected for RT-qPCR analysis as described above. Cells not treated with Griffithsin were used as a control.

\section{Cell-to-cell spread assay}

Cell-to-cell spread was assessed as previously described [7, 19] with some modifications. Vero cells were incubated with PEDV $(\mathrm{MOI}=3)$ at $37{ }^{\circ} \mathrm{C}$ for $3 \mathrm{~h}$ and washed with PBS to remove unbound virions. Then cells were cultured in fresh medium containing Griffithsin and monoclonal neutralizing antibody ( $\mathrm{nAb}$ ) (a generous gift from Haoming Zhang). Cells cultured in medium containing nAb but no Griffithsin served as a control. After $48 \mathrm{~h}$ incubation, the cells were fixed with pre-cooled methanol for indirect immunofluorescence assays.

\section{Data analysis}

Data were presented as the means \pm standard deviations of three independent experiments. Differences between group means were analyzed using the Student's $t$ test with GraphPad Prism 6 software. Statistical significance was assumed for $P<0.05$.

\section{Results}

\section{Expression of recombinant Griffithsin}

We designed a recombinant gene encoding Griffithsin with a His6 tag at it C-terminus. Recombinant Griffithsin was analyzed by SDS-PAGE and western blotting using antiHis monoclonal antibody as shown in Fig. 1. We observed

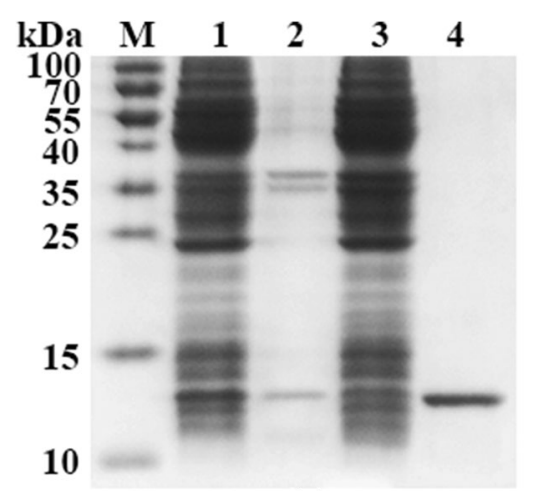

(a)

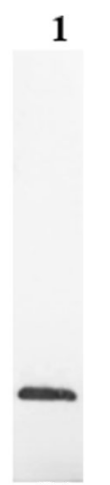

(b)
Fig. 1 Characterization of recombinant Griffithsin. a Using SDSPAGE. Lane M protein size markers, Lane 1 supernatant of $E$. coli bearing recombinant expression vector after induction with IPTG and high-pressure homogenization, Lane 2 pellet of $E$. coli bearing recombinant expression vector after induction with IPTG and highpressure homogenization, Lane 3 total cell extract of E. coli bearing recombinant expression vector without induction by IPTG, Lane 4 Griffithsin purified by nickel affinity chromatography. b Western blotting analysis using an anti-His tag antibody. Lane 1 Griffithsin purified by nickel affinity chromatography 
a band of the expected molecular weight (12.7 kDa). The majority of the recombinant Griffithsin protein was present in the E. coli cytoplasm in soluble form. The purified protein was dialyzed, following by endotoxin removal and filter sterilization prior to use.

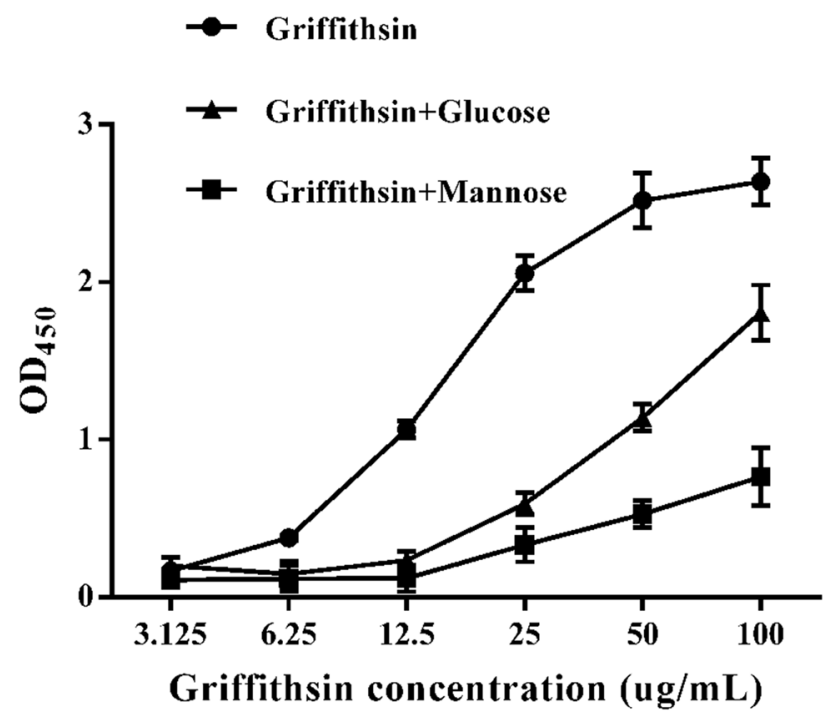

Fig. 2 ELISA binding of Griffithsin (circles), Griffithsin pre-incubated with mannose (squares) or Griffithsin pre-incubated with glucose (triangles) to PEDV virions

\section{Binding of Griffithsin to PEDV}

To investigate whether Griffithsin could bind to PEDV, we performed ELISA against immobilized PEDV virions as previously described [20]. The ELISA experiment demonstrated that Griffithsin could bind to PEDV in a dosedependent manner as shown in Fig. 2. Moreover, Griffithsin binding to PEDV was efficiently inhibited when it was preincubated with mannose or glucose (Fig. 2), indicating that PEDV glycans may be involved in the binding of Griffithsin to PEDV. These data implied potential antiviral activity of Griffithsin against PEDV.

\section{Griffithsin inhibits PEDV infection of Vero cells}

Antiviral assays were performed to determine whether binding of Griffithsin to PEDV affected its infectivity. The effects of Griffithsin at concentrations of $1,2,4,8 \mu \mathrm{g} / \mathrm{mL}$ on PEDV infection of Vero cells are shown in Fig. 3. Pre-incubation of PEDV with Griffithsin resulted in a significant reduction in infection compared with untreated PEDV virions. After infection of Vero cells with PEDV at a MOI of 5, the infection rate decreased from $92.5 \%$ (in the absence of Griffithsin treatment) to $60 \%$ and $14.43 \%$ in the presence of $1 \mu \mathrm{g} / \mathrm{mL}$ and $8 \mu \mathrm{g} / \mathrm{mL}$ Griffithsin, respectively. Griffithsin exhibited a much stronger inhibitory effect when Vero cells were infected at a MOI of 3: the infection rate decreased from $89.1 \%$ (in the absence of Griffithsin treatment) to $47.5 \%$
Fig. 3 Anti-PEDV activity of Griffithsin detected by immunofluorescence microscopy. a Indirect immunofluorescence assay of PEDV-infected Vero cells was performed to detect the antiviral activity of increasing concentrations of Griffithsin. N.I.: non-infected control. b Quantitation of PEDV-infected cells after treatment of Griffithsin. The results are expressed as percent-infected cells calculated from the number of infected cells (FITC stain)/ total number of cells (DAPI nuclei stain) $\times 100 \%$. Each value represents the mean of three independent experiments and its standard deviation. $* P<0.05$, $* * P<0.01$ and $* * * P<0.001$ compared with the $0 \mu \mathrm{g} / \mathrm{mL}$ control group. In both $\mathbf{a}$ and $\mathbf{b}$, $8+$ M: Griffithsin at concentration of $8 \mu \mathrm{g} / \mathrm{mL}$ was pre-incubated with mannose (a)

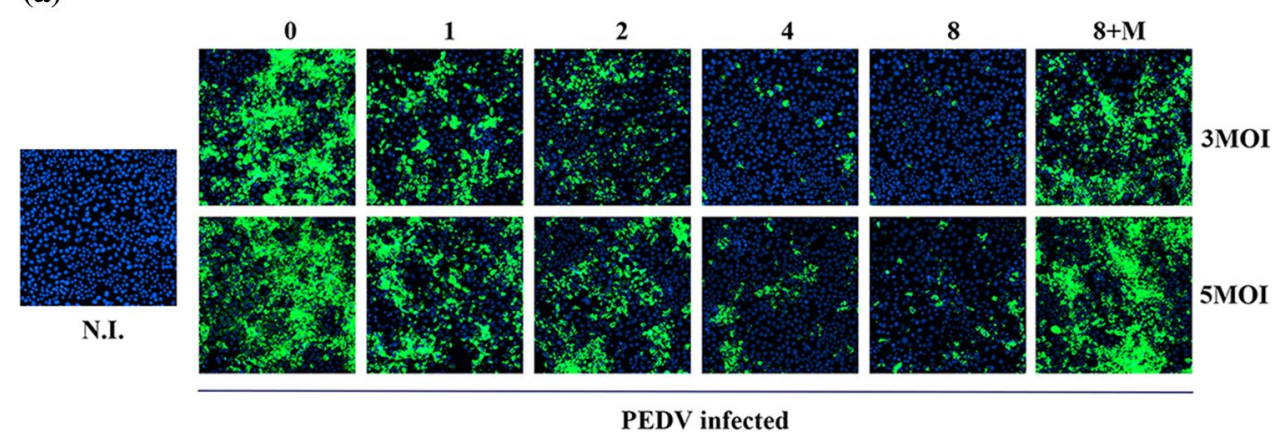

(b)

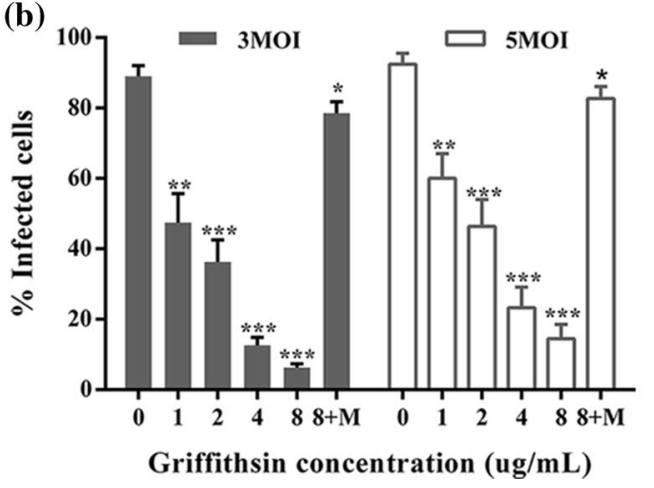


and $6.3 \%$ in the presence of $1 \mu \mathrm{g} / \mathrm{mL}$ and $8 \mu \mathrm{g} / \mathrm{mL}$ Griffithsin, respectively. As shown in Fig. 3, Griffithsin inhibited PEDV infection in a dose-dependent manner, and its inhibitory effect was lost when Griffithsin was pre-incubated with mannose.

The cytotoxicity of Griffithsin against Vero cells was studied, and the results showed that the proliferative activity of Vero cells was unaffected by Griffithsin at concentrations ranging from 1 to $10 \mu \mathrm{g} / \mathrm{mL}$. These results suggested that Griffithsin possessed antiviral activity against PEDV but no cytotoxic activity against mammalian cells.

\section{Time course of Griffithsin addition}

A time-of-addition assay was conducted to evaluate whether Griffithsin's inhibitory efficacy varied during different periods of PEDV infection (before, during and after). Viral RNA levels in Vero cells were quantitated $24 \mathrm{~h}$ after the last Griffithsin addition. Surprisingly, as shown in Fig. 4, addition of Griffithsin resulted in a significant reduction of viral RNA levels at all time points compared with the virus alone control $(P<0.001)$. Moreover, we found that delayed addition of Griffithsin resulted in a weaker inhibitory effect on PEDV. Griffithsin completely suppressed PEDV infection when added before or during virus inoculation $(0 \mathrm{~h})$; however, viral RNA loads exhibited similar reductions when Griffithsin was added after virus inoculation $(1,2,4,6,8$, $12 \mathrm{~h}$ ). By contrast, Griffithsin showed only a modest inhibitory effect when added $24 \mathrm{~h}$ post-virus inoculation, with viral RNA loads 135-fold higher compared with addition $12 \mathrm{~h}$ post-inoculation. These data indicated that Griffithsin had a stronger inhibitory effect during the initial stages of PEDV infection.

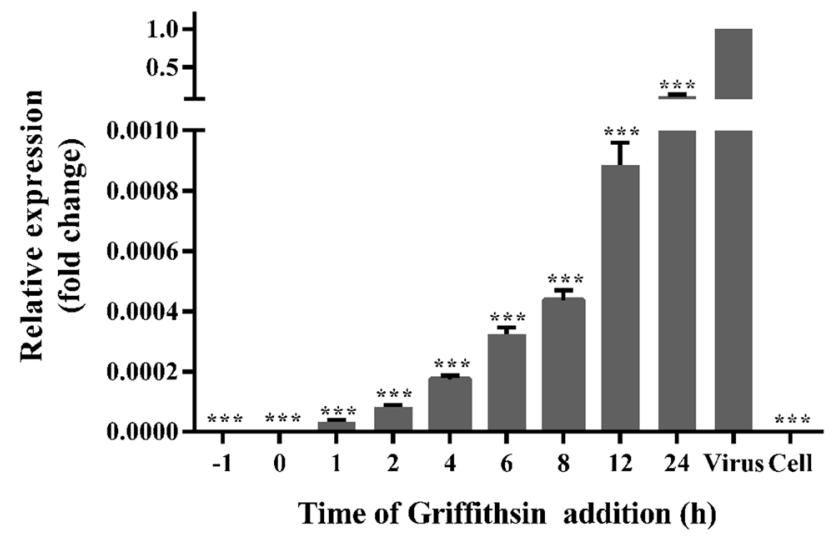

Fig. 4 Effect of Griffithsin on PEDV entry stages. In the control group, cells were infected with PEDV without Griffithsin treatment at any stage. Data are presented as means \pm standard deviations of three independent experiments. $* P<0.05, * * P<0.01$, $* * * P<0.001 \mathrm{com}-$ pared with the control group

\section{Effect of Griffithsin on PEDV entry stages}

To further understand the antiviral mechanisms of Griffithsin against PEDV, its effect on viral attachment and penetration was evaluated. The results clearly showed that Griffithsin could block viral attachment and had only modest effects on viral penetration (Fig. 5). The attachment assay showed that viral RNA loads were reduced approximately tenfold compared with control cells $(P<0.001)$. However, Griffithsin had little effect on infection when added during viral penetration $(P>0.05)$. Viral RNA loads were unaffected by Griffithsin addition compared with the control group when it was pre-incubated with mannose.

\section{Griffithsin inhibits cell-to-cell spread of PEDV}

Although it was uncertain whether PEDV can spread by direct cell-to-cell contact without passing through a cellfree stage, cell-to-cell spread has been observed in studies of many enveloped viruses. Thus, we speculated that cellto-cell spread of PEDV could be inhibited by Griffithsin. A monoclonal $\mathrm{nAb}$ was added to completely neutralize any released virions. PEDV cell-to-cell transmission was clearly efficiently suppressed by Griffithsin, as shown in Fig. 6a, $\mathrm{b}$, which caused a significant reduction in the number of PEDV-infected cells in a dose-dependent manner. The infection rate was reduced from $65.3 \%$ in cells treated with $\mathrm{nAb}$ alone to $27.3 \%$ and $12 \%$ in cells treated with $4 \mu \mathrm{g} / \mathrm{mL}$ and $8 \mu \mathrm{g} / \mathrm{mL}$ Griffithsin, respectively. Interestingly, the infection

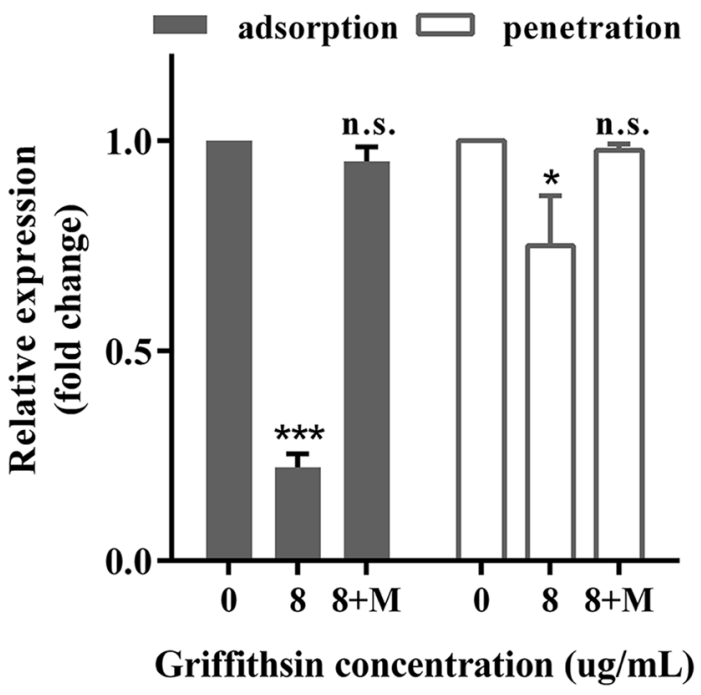

Fig. 5 Time-of-addition effect of Griffithsin on PEDV infection on Vero cells. Viral loads were quantitated using RT-qPCR. 8+M: Griffithsin at concentration of $8 \mu \mathrm{g} / \mathrm{mL}$ was pre-incubated with mannose. Data are presented as means \pm standard deviations of three independent experiments. $* P<0.05$, $* * P<0.01$, $* * * P<0.001$ compared with the control group 

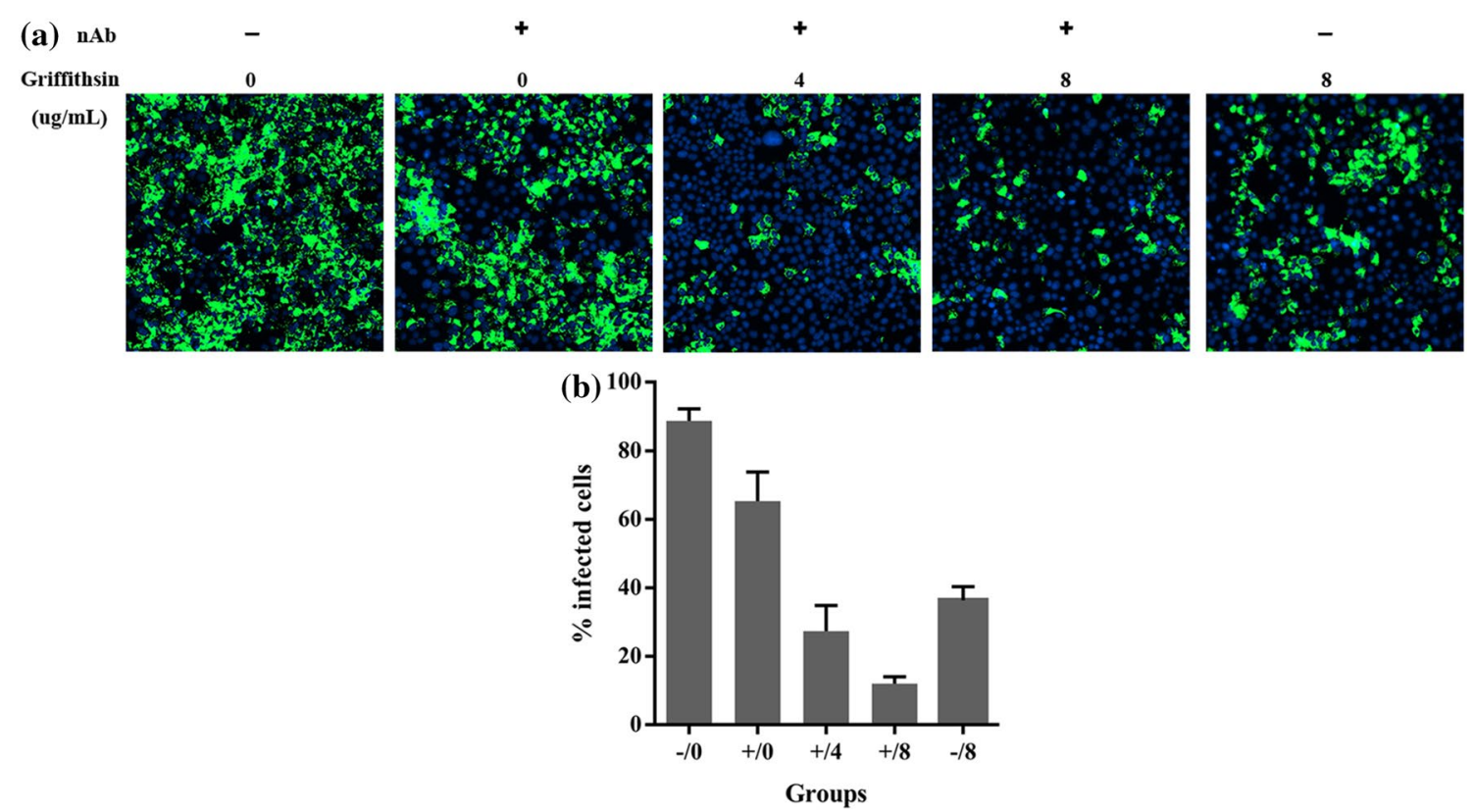

Fig. 6 Effect of Griffithsin treatment on PEDV cell-to-cell spread using immunofluorescence microscopy. a An indirect immunofluorescence assay was performed to assess the effect of Griffithsin on cellto-cell spread of PEDV. b Quantitation of PEDV-infected cells after

rate was reduced to $36.3 \%$ which showed stronger antiviral activity compared with the group treated with $\mathrm{nAb}$ alone. Importantly, Griffithsin also promoted the formation of discrete foci of infection.

\section{Discussion}

In this study, we provided initial evidence that Griffithsin has antiviral activity against PEDV. Moreover, its antiviral mechanism of action means that Griffithsin may represent an attractive drug for chemotherapeutic intervention. Griffithsin was not only able to prevent infection by cell-free virus, but was also able to prevent viral spread between infected and uninfected cells. This property may make Griffithsin superior to other antiviral drugs. Thus, Griffithsin may be a promising tool in combating PEDV.

Griffithsin bound PEDV in a glycan-dependent manner indicating that Griffithsin's antiviral activity may depend on interactions with viral glycans. We demonstrated that $8 \mu \mathrm{g} / \mathrm{mL}$ Griffithsin reduced infection by $82.8 \%$ when Vero cells were infected with PEDV at a MOI of 3. Furthermore, $4 \mu \mathrm{g} / \mathrm{mL}$ Griffithsin reduced PEDV infection of Vero cells by $69.2 \%$; by contrast, the same concentration reduced infection by $76.9 \%$ when Marc-145 cells were infected with PRRSV at a MOI of five in our previous study. Griffithsin also displayed antiviral activity against other enveloped viruses to various degrees and had much more potent activity against treatment with Griffithsin. Each value represents the mean of three independent experiments and its standard deviation. "-": no nAb was added, "+": nAb was added, Arabic numerals 0, 4, 8: the concentration of Griffithsin

HIV compared with the results shown here for PEDV [2]. The reasons underlying this difference are not completely understood, but the following potential causes may provide part of the explanation. Firstly, the structure and composition of glycans, as well as the glycosylation level of envelope glycoproteins, may affect the binding affinity of Griffithsin which is a major determinant of its antiviral activity. Secondly, the density of envelope spikes may be an important factor in determining Griffithsin activity. HIV-1 virions have an average of 14 spikes per virion particle [21] (compared with 450 for influenza type A virus [22]) and as few as four spikes are sufficient for HIV infection [23]; thus, to block infection by one HIV virion, Griffithsin must neutralize only four spikes. This probably explains why Griffithsin displayed a stronger inhibitory effect on HIV infection compared with other enveloped viruses.

Our data clearly showed that Griffithsin could block viral adsorption and had only modest effects on viral penetration. Most interestingly, we found that Griffithsin could inhibit PEDV infection by blocking cell-to-cell transmission. Our previous study showed that Griffithsin displayed antiviral activity against PRRSV by blocking virion attachment but not viral penetration. Moreover, studies have shown that the inhibition of MERS-CoV by Griffithsin might result from a failure of the virus to attach to target cells [5]. By contrast, Nixon reported that Griffithsin inhibited HSV-2 infection by disrupting cell-to-cell spread, not by acting on the entry stage [7]. The reason for 
this difference in mechanism of action may be related to the virus itself and its receptors. The detailed mechanisms remain to be explored in the future studies.

To understand the mechanism of action of Griffithsin on PEDV in more detail, we assessed Griffithsin's inhibitory efficacy when it was added at different stages of PEDV infection. Griffithsin treatment caused a significant reduction of viral RNA loads at all times of addition. Addition of Griffithsin before and during viral inoculation $(0 \mathrm{~h})$ caused a $10^{5}$-fold reduction in viral loads compared with uninfected cells; by contrast, addition of Griffithsin $1-2,4-12$ and $24 \mathrm{~h}$ post-inoculation caused $10^{4}-, 10^{3}$ - and eightfold reductions in viral loads, respectively. This finding indicated that earlier treatment with Griffithsin resulted in stronger inhibitory effects against PEDV infection.

The antiviral activity of Griffithsin in vivo has been widely studied. The in vivo efficacy of Griffithsin against SARS-CoV [24], HSV-2 [7], JEV [9] and HCV [6, 25] was evaluated in murine models, and the results showed that Griffithsin treatment had a protective effect as shown by animal weight, morbidity, mortality and target tissue viral titer. Interestingly, Barry and his colleagues [24] indicated that SARS-CoV-infected mice treated with Griffithsin did not lose weight and had $100 \%$ survival; however, mice not treated with Griffithsin experienced a $25 \%$ decrease in weight and had just a 30\% survival rate. Moreover, bioavailability studies $[26,27]$ in animals demonstrated that Griffithsin could accumulate to high levels in serum after subcutaneous delivery and that serum from Griffithsin-treated animals retained antiviral activity; these findings suggested that Griffithsin may be a promising candidate as a systemic antiviral therapeutic. Further studies in live animals will be necessary to confirm the value of inhibiting PEDV infection in vivo, potentially leading to a new antiviral intervention.

In conclusion, we found that Griffithsin had potent anti-PEDV activity via prevention of viral attachment and cell-to-cell spread. Moreover, our study revealed that Griffithsin exhibited a stronger effect on PEDV infection when it was added during early stages of infection. Further studies in live animals will be necessary to develop a novel antiviral strategy for PEDV therapy.

Acknowledgements This study was supported by grants from the Special Fund for Agro-scientific Research in the Public Interest (No. 201303046) and the National Natural Science Foundation of China (No. 31772701 and No. 31502105).

\section{Compliance with ethical standards}

Conflict of interest The authors declare that they have no conflicts of interest.

Ethical approval This article does not contain any studies with human participants or animals performed by any of the authors.

\section{References}

1. Mori T, O’Keefe BR, Sowder RC, Bringans S, Gardella R, Berg S, Cochran P, Turpin JA, Buckheit RW Jr, McMahon JB, Boyd MR (2005) Isolation and characterization of Griffithsin, a novel HIV-inactivating protein, from the red alga Griffithsia sp. J Biol Chem 280(10):9345-9353

2. Lusvarghi S, Bewley CA (2016) Griffithsin: an antiviral lectin with outstanding therapeutic potential. Viruses 8(10):296

3. Xue J (2014) Investigation of the mechanism of griffithsin (GRFT): a potent HIV entry inhibitor. Dissertations \& Theses-Gradworks

4. Ziolkowska N, O'Keefe BR, Mori T, Zhu C, Giomarelli B, Vojdani F, Palmer K, McMahon JB, Wlodawer A (2006) Domain-swapped structure of the potent antiviral protein griffithsin and its mode of carbohydrate binding. Structure 14(7): 1127

5. Millet JK, Séron K, Labitt RN, Danneels A, Palmer KE, Whittaker GR, Dubuisson J, Belouzard S (2016) Middle East respiratory syndrome coronavirus infection is inhibited by griffithsin. Antiviral Res 133:1

6. Takebe Y, Saucedo CJ, Lund G, Uenishi R, Hase S, Tsuchiura T, Kneteman N, Ramessar K, Tyrrell DL, Shirakura M (2013) Antiviral lectins from red and blue-green algae show potent in vitro and in vivo activity against hepatitis $C$ virus. PLoS ONE 8(5):e64449

7. Nixon B, Stefanidou M, Mesquita PM, Fakioglu E, Segarra T, Rohan L, Halford W, Palmer KE, Herold BC (2013) Griffithsin protects mice from genital herpes by preventing cell-to-cell spread. J Virol 87(11):6257-6269

8. Ishag HZ, Li C, Wang F, Mao X (2016) Griffithsin binds to the glycosylated proteins (E and prM) of Japanese encephalitis virus and inhibit its infection. Virus Res 215:50-54

9. Ishag HZA, Li C, Huang L, Sun MX, Wang F, Ni B, Malik T, Chen PY, Mao X (2013) Griffithsin inhibits Japanese encephalitis virus infection in vitro and in vivo. Arch Virol 158(2):349-358

10. Levendosky K, Mizenina O, Martinelli E, Jeanpierre N, Kizima L, Rodriguez A, Kleinbeck K, Bonnaire T, Robbiani M, Zydowsky TM (2015) Griffithsin and carrageenan combination to target herpes simplex virus 2 and human papillomavirus. Antimicrob Agents Chemother 59(12):7290-7298

11. Kouokam JC, Huskens D, Schols D, Johannemann A, Riedell SK, Walter W, Walker JM, Matoba N, O'Keefe BR, Palmer KE (2011) Investigation of griffithsin's interactions with human cells confirms its outstanding safety and efficacy profile as a microbicide candidate. PLoS ONE 6(8):e22635

12. Fuqua JL, Wanga V, Palmer KE (2015) Improving the large scale purification of the HIV microbicide, griffithsin. BMC Biotechnol 15(1):12

13. Moncla BJ, Pryke K, Rohan LC, Graebing PW (2011) Degradation of naturally occurring and engineered antimicrobial peptides by proteases. Adv Biosci Biotechnol 2(6):404-408

14. Diel DG, Lawson S, Okda F, Singrey A, Clement T, Fernandes MH, Christopher-Hennings J, Nelson EA (2016) Porcine epidemic diarrhea virus: an overview of current virological and serological diagnostic methods. Virus Res 226:60-70

15. Wang D, Fang L, Xiao S (2016) Porcine epidemic diarrhea in China. Virus Res 226:7-13

16. Li HJ, Gao DS, Li YT, Wang YS, Liu HY, Zhao J (2018) Antiviral effect of lithium chloride on porcine epidemic diarrhea virus in vitro. Res Vet Sci 118:288-294

17. Lee $C$ (2015) Porcine epidemic diarrhea virus: an emerging and re-emerging epizootic swine virus. Virol J 12(1):1-16

18. Hwajung C, Jinhee K, Choonghwan L, Youngjoon A, Song JH, Seunghwa B, Durhan K (2009) Antiviral activity of quercetin 
7-rhamnoside against porcine epidemic diarrhea virus. Antiviral Res 81(1):77-81

19. Yang Q, Gao L, Si J, Sun Y, Liu J, Cao L, Feng WH (2013) Inhibition of porcine reproductive and respiratory syndrome virus replication by flavaspidic acid AB. Antiviral Res 97(1):66-73

20. Keirstead ND, Lee C, Yoo D, Brooks AS, Hayes MA (2008) Porcine plasma ficolin binds and reduces infectivity of porcine reproductive and respiratory syndrome virus (PRRSV) in vitro. Antiviral Res 77(1):28-38

21. Zhu P, Liu J, Bess J, Chertova E, Lifson JD, Grisé H, Ofek GA, Taylor KA, Roux KH (2006) Distribution and threedimensional structure of AIDS virus envelope spikes. Nature 441(7095):847-852

22. Yamaguchi M, Danev R, Nishiyama K, Sugawara K, Nagayama K (2008) Zernike phase contrast electron microscopy of ice-embedded influenza A virus. J Struct Biol 162(2):271-276

23. Sougrat R, Bartesaghi A, Lifson JD, Bennett AE, Bess JW, Zabransky DJ, Subramaniam S (2007) Electron tomography of the contact between T cells and SIV/HIV-1: implications for viral entry. PLoS Pathog 3(5):e63

24. O'Keefe BR, Giomarelli B, Barnard DL, Shenoy SR, Chan PKS, Mcmahon JB, Palmer KE, Barnett BW, Meyerholz DK,
Wohlfordlenane CL (2010) Broad-spectrum in vitro activity and in vivo efficacy of the antiviral protein griffithsin against emerging viruses of the family Coronaviridae. J Virol 84(5):2511-2521

25. Meuleman P, Albecka A, Belouzard S, Vercauteren K, Verhoye L, Wychowski C, Lerouxroels G, Palmer KE, Dubuisson J (2011) Griffithsin has antiviral activity against hepatitis $\mathrm{C}$ virus. Antimicrob Agents Chemother 55(11):5159-5167

26. Barton C, Kouokam J, Hurst H, Palmer K (2016) Pharmacokinetics of the antiviral lectin griffithsin administered by different routes indicates multiple potential uses. Viruses 8(12):331

27. Barton C, Kouokam JC, Lasnik AB, Foreman O, Cambon A, Brock G, Montefiori DC, Vojdani F, Mccormick AA, O'Keefe BR (2014) Activity of and effect of subcutaneous treatment with the broad-spectrum antiviral lectin griffithsin in two laboratory rodent models. Antimicrob Agents Chemother 58(1):120-127

Publisher's Note Springer Nature remains neutral with regard to jurisdictional claims in published maps and institutional affiliations. 